\title{
O que faz do grupo um dispositivo analítico? Considerações de Freud e Lacan
}

\author{
Danna De Luccia* \\ Léia Priszkulnik (iD) \\ Universidade de São Paulo, Departamento de Psicologia Clínica. São Paulo, SP, Brasil
}

Resumo: O intuito deste artigo é retomar a discussão sobre a prática clínica com grupos a partir da psicanálise de Freud e de Lacan, tendo como horizonte ressaltar a ética do psicanalista, seus impasses e suas possibilidades de inserção em espaços coletivos, públicos ou institucionais. O recurso ao coletivo é uma característica privilegiada na atenção psicossocial e na "clínica ampliada" preconizada pelo Sistema Único de Saúde (SUS). Contudo, vê-se com frequência a diluição da perspectiva inovadora proposta no surgimento dos grupos no campo clínico e o predomínio do atendimento massificado, o que justifica esta retomada clínica. Para isto, apresentamos contrapontos entre os grupalistas no interior da psicanálise e a perspectiva lacaniana acerca da lógica coletiva e do laço social. Em seguida, retomamos alguns trabalhos de extração lacaniana em diferentes contextos coletivos e, por último, enfatizamos algumas considerações sobre a prática clínica, tendo como norte atravessar os efeitos imaginários do grupo e privilegiar o sujeito e sua singularidade.

Palavras-chave: psicanálise, grupos, instituições, Freud, Lacan.

\section{Introdução}

A inscrição da psicanálise nas instituições, nos espaços públicos e no campo social é um tema bastante visitado por diferentes autores que assinalam a necessidade de ampliação da reflexão sobre a atuação do psicanalista nestes contextos. Os grupos podem ser uma ferramenta privilegiada para a prática psicanalítica na atualidade, compondo um dispositivo clínico e político tanto para as situações sociais limites, o que inclui a crescente degradação das condições de vida, segregação e incremento do individualismo, quanto para as situações clínicas limites, como depressões, fenômenos borderline, adicções, pânico, entre outros, que com frequência se sobrepõem, gerando importantes impasses na subjetivação e nas possibilidades de laço social.

Apesar de não carregar um pertencimento clínico de origem, o trabalho com grupos tornou-se frequente em instituições de saúde. Nos tempos de repressão política, em meados da década de 1960 e 1970, o campo clínico grupal trazia uma perspectiva inovadora ao propiciar uma lógica coletiva de reflexão, resistência e transformação. Atualmente, contudo, vê-se a diluição desta perspectiva e a predominância de efeitos de massificação, seja no âmbito clínico, no qual os grupos acabam sendo vistos como redução das filas de espera, seja em outras formações institucionais, sociais e políticas, geralmente centradas na figura do líder ou da ideologia, com seus conhecidos efeitos de alienação, já descritos por Freud em 1921.

Desta forma, buscaremos elementos para responder à questão que comumente move os psicanalistas

* Endereço para correspondência: dannapaes@gmail.com que operam nesta prática: em que a psicanálise pode contribuir para a clínica com grupos, preservando aquilo que é próprio da psicanálise, que é abarcar a dimensão do sujeito em sua singularidade e escapar dos efeitos de massificação? E, ainda, o questionamento sobre o que torna o grupo um dispositivo analítico. A hipótese expressa nesse artigo é de que o resgate e a atualização da aplicabilidade conceitual das teorias grupais na psicanálise, acrescidos das contribuições de Lacan acerca da lógica coletiva, serão de grande valia à inserção da psicanálise em diferentes contextos coletivos da atualidade.

No campo psicanalítico, o tema já carrega uma tradição, com os renomados trabalhos de Pichon-Rivière, Bion, Anzieu e Kaës, para citar alguns dos principais grupalistas no interior da psicanálise. Em comparação a estes trabalhos, ainda há pouca bibliografia no interior da teoria do campo lacaniano para se pensar o grupo na prática clínica, talvez por um limite colocado pelo próprio Lacan (1998), que alertava para os efeitos nefastos do imaginário alienante no grupo. No entanto, mostraremos que o tema do grupo está longe de ser estranho para Lacan. As pesquisas lacanianas sobre o dispositivo de cartel, a lógica coletiva e a teoria dos discursos no laço social foram todas desenvolvidas para se pensar o espaço compartilhado entre os sujeitos a partir de uma estratégia capaz de reduzir o efeito alienante e imaginário do grupo. Tais efeitos, descritos por Freud em "Psicologia de Grupo e Análise do Ego" (1921/2006), seriam derivados do fenômeno regressivo em massas organizadas em torno de um líder ou de uma ideologia.

Determina-se como ponto de partida deste trabalho retomar algumas teorias de grupo na psicanálise e fazer um contraponto a elas com algumas considerações 
lacanianas sobre o tema. Esta opção metodológica leva em conta a diferença fundamental da concepção entre as escolas de psicanálise no que tange ao encontro com mais de "um outro" e suas respectivas trocas subjetivas.

A etapa seguinte consistirá em mostrar exemplos de práticas grupais desenvolvidas por psicanalistas de extração lacaniana que, embora heterogêneas e situadas em diferentes níveis de atuação clínica, evidenciam a pertinência das proposições lacanianas para a construção de dispositivos clínicos grupais. Reuniremos aspectos que ajudem a pensar a posição do analista na coordenação de grupos de modo que seja propiciadora da potência clínica do coletivo para além do imaginário, para o questionamento das posições cristalizadas de gozo e para a criação de novas formas de se relacionar no laço social. O intuito, por fim, será articular os elementos teóricos acerca do coletivo e dos laços sociais para compor ferramentas aplicáveis ao campo clínico grupal.

\section{Os grupos na clínica: um breve resgate histórico}

As psicoterapias grupais sofreram influência de inúmeras teorias. No início, da psicanálise e das ideias marxistas, depois da psicologia da Gestalt e da teoria do campo e, mais tarde, da teoria da comunicação, que trouxe uma visão interdependente entre indivíduo e grupo. Influenciado pelos conceitos empregados por Tarde e Le Bon para o estudo das multidões e pela conjectura histórica após a Primeira Guerra, Freud deu um salto na compreensão das massas ao trazer contribuições teóricas acerca dos laços emocionais e inconscientes que atravessariam os conceitos de imitação em Tarde e de sugestão mútua e prestígio dos líderes em Le Bon. Desta forma, Freud, em "Psicologia de Grupo e Análise do Ego" (1921/2006), introduziu uma concepção da constituição do laço social com a tese psicanalítica de que a identificação entre os indivíduos e a colocação de um líder no lugar de ideal de Eu são sustentadas pelo investimento libidinal, destacando também o conflito entre as necessidades narcísicas e os vínculos grupais e o estado de regressão primitiva envolvida na psicologia das massas, semelhante ao mito simbólico do pai da horda primeva que Freud descreve em "Totem e Tabu" (1913/2006).

O conceito de identificação foi central para a compreensão da natureza dos grupos na medida em que é através das identificações que o indivíduo se constitui. Nos grupos, são predominantes dois tipos de identificação: a identificação regressiva, na qual o líder é colocado no lugar de ideal, e a identificação histérica, com o outro semelhante. A pesquisa de Freud seguiu dois níveis de análise, a primeira concentrou-se sobre a psicologia das massas e suas modificações no indivíduo e a segunda deu continuidade ao estudo metapsicológico empreendido, especialmente em "Sobre o narcisismo: uma introdução" (1914/2006); "Luto e Melancolia" (1917/2006) e "O ego e o id" (1923/2006) posteriormente (Penna, 2014).
Embora Freud nunca tenha trabalhado diretamente com grupos na clínica, seu arcabouço teórico sobre os grandes grupos contribuiu para as primeiras tentativas de aplicação da psicanálise ao trabalho com pequenos grupos no século XX, como as realizadas por Adler, que desenvolveu antes da Primeira Guerra grupos com operários e em clínicas de orientação infantil, e Ernst Simmel, que propôs um tratamento para neuróticos de guerra em grupo por meio do método catártico. Jacob Moreno desenvolveu a técnica psicodramática na Europa através do "teatro espontâneo", abrindo espaço para os primeiros grupos terapêuticos e, também, para a denominação "psicoterapia de grupo" no cenário clínico em 1931. Nos Estados Unidos, entre as décadas de 1930 e 1940, houve o notório trabalho de Kurt Lewin (1978), que associou as ciências sociais à Gestalttheorie para desenvolver um corpo teórico sobre grupos ao atentar para a diferença entre a soma das partes e o grupo. Isto é, o grupo teria uma totalidade dinâmica e o todo seria considerado mais do que a soma das partes, acrescentando-se a este enunciado as relações de figura e de fundo para se pensar os grupos terapêuticos (Penna, 2014).

As ideias de Lewin influenciaram também os trabalhos de inspiração psicanalítica a partir da Segunda Guerra Mundial. Na psicanálise inglesa, Foulkes conceituou a grupanálise (Group Analysis) e Rickman e Bion desenvolveram a psicodinâmica de grupo nos "grupos de trabalho". Na Argentina, entre os anos 1940 e 1950, Pichon-Rivière cria o grupo operativo centrado na tarefa, surgido, por sua vez, a partir de sua mítica intervenção no Hospício de Las Mercedes, onde trabalhou como médico por 15 anos. Mais recentemente, acrescenta- se os trabalhos dos representantes da Escola Francesa, com Didier Anzieu, que a partir da década de 1960 usou as dinâmicas de Lewin para desenvolver suas primeiras pesquisas com psicanálise e grupos e seu discípulo René Kaës, que a partir dos anos 1970 enfatizou as relações intersubjetivas no interior da psicanálise.

Bion (1961/1975), em sua teoria de grupos, partiu da ideia de uma regressão tópica às fases primitivas da vida mental (protomental) pertencentes à fase esquizoparanóide descrita por Melaine Klein. O grupo, assim, estaria sujeito a dois níveis de comportamento: o grupo defendido e aprisionado aos supostos básicos (dependência, luta-fuga e acasalamento) e o grupo de trabalho (produção de algo novo). Ainda que a travessia destes pressupostos básicos previsse o deslocamento da figura do líder, ou para um casal (acasalamento), objeto, ideologia, ou tarefa em comum, tal como pensado por Pichon-Rivière, as figuras identificatórias imaginárias continuariam operando.

Embora a teoria bioniana não seja suficiente para resolver o impasse do plano imaginário das identificações, ela foi de grande valia para o campo grupal, chamando a atenção de Lacan durante sua estadia de cinco semanas na Inglaterra em 1947, quando se debruçou sobre o artigo "A psiquiatria inglesa e a guerra" (1947/2003). Lacan demonstrou respeito ao trabalho realizado por 
Bion, descrevendo sua técnica como "grupo sem chefe", o que também contribuiu para seu pensamento acerca do dispositivo do cartel dentro da lógica coletiva, capaz de subverter a relação do grupo com o líder.

Kaës (2010) e Anzieu (1993) partem do recorte freudiano sobre o grupo e as representações imaginárias e da regressão diante das ameaças que o contexto grupal infligiria à integridade do ego. Kaës (2010) pensou o grupo através da circulação fantasmática, projeções e introjeções de cada um no grupo; a presença dos organizadores psíquicos inconscientes a respeito das relações objetais, a imagem corporal, a fantasia originária, os complexos familiares. Kaës (2010) concebe o trabalho analítico como o "trabalho da intersubjetividade" (p. 225), que gira em torno da análise das transferências interpessoais e da elaboração das transferências e contratransferências na configuração grupal. Anzieu (1993), por sua vez, enfatiza a dimensão imaginária, observando o que chamou de "ilusão grupal" e a necessidade de elaboração das angústias através da passagem do "si mesmo do grupo" para o "nós grupal", semelhante ao grupo de trabalho postulado por Bion. Embora o imaginário seja problematizado em Anzieu (1993) e, nesse sentido, fica mais próximo daquilo que se busca com Lacan, torna-se ao mesmo tempo dependente dos recursos imaginários para o acontecer grupal, com organizadores conceituais como a "imago", as "protofantasias", a "imagem do corpo próprio" e o "Eu-pele" (Costa-Rosa \& Pastori, 2011).

De acordo com Costa-Rosa e Pastori (2011), estes autores partem, cada um a seu modo, de uma hipótese de um "aparelho psíquico grupal". Apesar do mérito destas teorias, algumas delas acabaram aprisionadas a relações imaginárias centradas num processo regressivo, tanto as previstas por Freud na dinâmica das massas (protofantasias, eu ideal, dimensão imaginária do sonho) quanto as delineadas por Melanie Klein (posição esquizoparanóide, identificação projetiva e contratransferência).

Pensaremos agora com Lacan, e sua concepção de sujeito, alguns desdobramentos teóricos que possam contribuir para a passagem do imaginário ao simbólico. Isso não significa que não se sirva do imaginário, mas que o horizonte simbólico possa estar no horizonte analítico de maneira bem estabelecida. É fundamental esta ressalva, já que em alguns trabalhos encontrados parece haver uma dicotomia entre o campo imaginário e o simbólico nos grupos. Ressalta-se, portanto, a simultaneidade do trabalho nos três registros. O campo imaginário, das identificações, é fundamental para casos nos quais existe uma impossibilidade de se reconhecer como pertencente ao laço social. Alguns grupos não são propriamente analíticos, mas exercem uma importante função no reestabelecimento de laços e vínculos sociais. É o caso das oficinas, dos grupos de atividades e mesmo dos grupos psicoterapêuticos que promovem o processo de reconhecimento mútuo entre seus membros. Mas é igualmente importante que não se perca de vista o discurso do analista que sustenta o mal-estar para que a produção singular aconteça.

\section{Bases teóricas em Lacan para se pensar os grupos}

Lacan (1945/1998) extrai do texto freudiano "Psicologia de Grupo e Análise do Ego" (1921/2006) a ideia de que a escala coletiva é homogênea aos processos subjetivos do sujeito e de que o grupo se utiliza dos mesmos modos de defesa que o indivíduo utiliza na neurose (Laurent, 2002). O Outro e a cultura são traumáticos e o Eu é compreendido como uma instância de alienação que distancia o sujeito de sua verdade a partir das identificações imaginárias que condensam os ideais. Para Lacan, o Eu comporta eternamente o "efeito do grupo" dentro de si, como um acréscimo de obscenidade do efeito imaginário e alienante. $\mathrm{O}$ grupo externo, portanto, reforçaria este efeito do grupo interno, partícipe da constituição do sujeito enquanto sujeito dividido (Cavalcanti, 2006).

Diferente da escola inglesa e seus herdeiros, que concebem o reconhecimento do outro a partir de uma dialética na relação entre o interno e externo, para Lacan (1966/1998) o reconhecimento do outro como sujeito se dá desde sempre, pois a linguagem precede o nascimento. A linguagem é um lugar simbólico, composto pela cultura, família, sociedade ou por aquilo que denominou Grande Outro. Essa divergência não é insignificante se nos atentarmos para suas implicações na transferência, imaginária e simbólica.

Num primeiro momento da sua obra, por volta dos anos 1950, Lacan (1995) emprega o termo "intersubjetividade" como uma dimensão essencial para se pensar uma teoria do reconhecimento que busque qualificar a relação de sujeito a sujeito mediada pela linguagem, pelo lugar do Outro. Em 1967, contudo, o termo foi eclipsado por Lacan, tendo em vista que a relação entre sujeitos é sempre uma relação do sujeito ao Outro (Porge, 1994).

Lacan (1967/2003) coloca, então, o fenômeno psicanalítico da transferência como um obstáculo à intersubjetividade. A impossibilidade da coexistência de subjetividades se daria na medida em que o sujeito se relaciona com outro a partir de um constituinte ternário, ou seja, a partir de um significante inconsciente introduzido no discurso referente ao Outro. É por isso que para Lacan (1967/2003) o sujeito é suposto por outro sujeito, pois este sujeito é aquilo que um significante representa para outro significante.

De acordo com Quinet (2012), há cinco modalidades do outro em Lacan: o outro meu semelhante; o Outro lugar do inconsciente; o objeto a causa de desejo; o outro do laço social; e o Heteros, o Outro do gozo. Isso nos dá pistas iniciais sobre como o diálogo entre dois "eus" não envolve só os dois "eus"; envolve o "eu", consciente e inconsciente; o "outro", imagem e semelhante, e o "Outro", ordem simbólica. O Outro, do qual o inconsciente é discurso, também é variável histórica e cultural, dado que o sujeito se situa em relação ao saber e, este, é influenciado por valores de um tempo, tal como propõe Askofaré (2009). 
No contexto grupal, essas dimensões do outro coexistem. O sujeito se relaciona com o pequeno outro, semelhante, e com o Grande Outro, representante simbólico da autoridade e do Sujeito Suposto Saber na situação analítica, na medida em que o analisando supõem que o analista saiba algo acerca de seu sofrimento, a verdade sobre seu sintoma. Desse modo, o tema do grupo em Lacan (1998) parece colocar de saída a questão da transferência e sua relação com o Sujeito Suposto Saber, como ele mesmo reflete ao sugerir que a estrutura do grupo articulada por Freud em "Psicologia de Grupo e Análise do Ego" (1921/2006), cujos principais modelos seriam a Igreja e o Exército, favoreceu grandemente o pensamento sobre as identificações imaginárias e sobre a relação com o Sujeito Suposto Saber. Ao longo de toda sua obra, Lacan apresenta articulações sobre a dimensão relacional em referência ao Outro e a importância subjetiva deste lugar.

\section{Tempo lógico e a lógica coletiva}

Lacan sabia, em 1945, dos efeitos traumáticos da psicologia das massas diante dos horrores do nazismo e do louvor cego a Hitler e, por este motivo, se colocou a pensar um tipo possível de coletivo que estivesse fora da lógica do poder nefasto do significante-mestre associado ao líder. Assim, Lacan desenvolve o ponto que será aqui primeiro apresentado, que diz respeito a como favorecer identificações horizontais em detrimento das verticais.

Porge (1994) considera que Lacan resolve esta questão no texto exemplar "O tempo lógico e a asserção da certeza antecipada" (1945/1998), no qual busca examinar a relação de reciprocidade de sujeitos diante da ausência de um mestre. O exemplo se passa numa prisão, na qual três prisioneiros têm que resolver um problema lógico em troca da liberdade. O carcereiro não está presente, ele só comunica o problema: cada um deve descobrir a cor do disco que está nas próprias costas, sem se comunicarem e sabendo que há no total três brancos e dois pretos. O problema é resolvido em três tempos: instante de ver (percepção: "ninguém sai, logo não há dois pretos"); tempo de compreender ("a partir do movimento dos outros suponho que sou branco") e momento de concluir (a afirmação de uma subjetividade em um ato que verifica a certeza de ser branco em concomitância com os passos que os outros prisioneiros dão em direção à saída).

A lógica coletiva é a proposta de Lacan a este tipo de agrupamento de sujeitos que difere dos grupos tipo massa, no qual os sujeitos borram suas diferenças ao identificar-se ao líder. Trata-se de um grupo sem chefe, no qual os sujeitos não competem entre si, pois através da relação com uma causa vital, de uma falta em comum, se movem de maneira singular com a causa e concluem em um ato que libera juntos todos os sujeitos (Gallano, 2014). Vemos, a partir disto, que existem as duas possibilidades de grupo: grupo tipo massa e grupo tipo coletivo, tal como propôs Lacan acerca da relação entre os prisioneiros.
Embora Lacan tenha dado um passo atrás em relação à noção de intersubjetividade, já que cada sujeito se relaciona com outro a partir de sua subjetividade e de mundos distintos, a partir do exemplo do tempo lógico, Porge (1994) reposiciona a questão da intersubjetividade em Lacan se perguntando o que acontece na relação entre sujeitos quando ela ultrapassa o do mero encontro entre significantes. Existiria uma medida comum na multiplicidade de sujeitos que poderia fundar, afinal, uma intersubjetividade? $\mathrm{O}$ ato dos prisioneiros no tempo lógico permite estabelecer, na saída, no ato do momento de concluir, uma "medida comum", reflete Porge (1994, p. 195)

Em 1973, o próprio Lacan volta ao tempo lógico com um desenvolvimento teórico inesperado sobre a saída dos prisioneiros: "há algo aí de que apenas valorizei o fato de que algo como uma intersubjetividade pode levar a uma saída salutar" (Lacan apud Porge, 1994, p. 116). Sobre esta colocação, Porge (1994) conclui que o objeto $a$, manifesto na pressa para concluir (a-pressado), é o "elo a mais", que só existe a partir de um percurso temporal dentro de uma relação entre os três prisioneiros: "mesmo que sejam apenas três, isso dará quatro" (p. 199).

Diferente da identidade imaginária estabelecida através do líder da massa descrita por Freud, Lacan coloca em jogo nesta proposta de lógica coletiva um certo tipo de “identificação saudável" como descreve Cevasco (2014). Cada prisioneiro está situado a partir de sua posição de excluído (não saber sua cor, não saber quem é). Cada um deles se relaciona a partir de uma falta comum e não de um líder, condição que funda uma experiência coletiva que permite uma subjetividade, mas não sem a existência dos outros.

Jasiner (2008), ao pensar o grupo centrado numa tarefa, traz uma alternativa semelhante à de Porge ao propor que o centro do grupo (a tarefa) é o objeto (a) que incide sobre o sujeito, em seu corpo, enquanto um resto não simbolizável, que circunscreve os modos de gozo e, ao mesmo tempo, move os sujeitos numa mesma direção. A tarefa com outros é, portanto, contornar o furo que está no centro do grupo. Isto é algo fundamental para se pensar na experiência com grupos que compartilham um tipo de falta; na realidade, é deste compartilhamento que se trata: do objeto $a$ e das formas de sofrimento mais diretamente a ele relacionadas.

\section{O cartel como tática da lógica coletiva e das relações institucionais}

Lacan (1998) iniciou suas primeiras formulações sobre o dispositivo de cartel em 1964 no ato de fundação da Escola Freudiana de Paris (EFP). Diferente de um grupo de estudos, o cartel deveria ter, em primeiro plano, o intuito de escapar da lógica das massas, na qual o líder preencheria o lugar de Outro ou de Sujeito Suposto Saber dentro do imaginário grupal. A identificação ao líder, embora satisfatória e confortável ao sujeito, inibiria a produção de saber. Nesse sentido, o Mais-um escolhido 
pelo grupo deve trabalhar para subverter essa lógica e sustentar a inconsistência do Outro (Pomponet, 2013).

Em março de 1980, Lacan intensificou suas reflexões acerca do Sujeito Suposto Saber nas relações estruturadas em instituições psicanalíticas ao perceber que os grupos de sua própria escola de psicanálise haviam se formado mais pela lógica das massas do que pela do coletivo. Assim, em meio a dissolução da EFP, Lacan sugere a estratégia do corte dissolutivo para minimizar os efeitos hierárquicos, formalizando a estrutura do cartel no texto intitulado “D’Écolage" (Lacan, 1980), derivado, por sua vez, da experiência adquirida com as Jornadas de Cartéis. O grupo assim só teria sentido se atrelado a um trabalho cuja dissolução estivesse prevista, e essa seria a solução para qualquer tentativa de trabalho em grupo, o que extrapolava os limites da própria escola.

A insistência de Lacan com o dispositivo de cartel vai ao encontro de uma aposta política que coloca em debate os enganos que as identificações imaginárias promovem na relação que o sujeito estabelece com seu ideal. Esse efeito de cola no grupo inviabilizaria qualquer tipo de movimento em relação ao saber. De acordo com Gomes (2015), o cartel propõe justamente trabalhar com os efeitos de cola sem tamponar o real que perpassa os grupos.

\section{Teoria dos discursos}

A teoria lacaniana dos discursos, exposta entre 1969 e 1970 no seminário 17 "O Avesso da Psicanálise", é composta por modos de se pensar o laço social. Os laços, de acordo com Lacan (2006), são estruturados pela linguagem e as quatro formas de discurso (do Mestre, da histérica, do universitário e do analista) ordenam distintos modos de se dirigir ao Outro e de gozar. A lógica dos discursos é também distribuída em quatro lugares separados por barras: agente/verdade, outro/produção. Os lugares são fixos, e os discursos são móveis, cada um deles se organiza de determinada maneira sobre os lugares.

O discurso do Mestre é aquele cujo laço está baseado no poder: o Mestre dita aquilo que se coloca como ideal, o que ordena o saber do grupo e permite a governabilidade. De qualquer forma, é verdade que a figura do Mestre e sua autoridade atravessa as relações sociais e, nesse sentido, o discurso do Mestre é organizador da sociedade em que vivemos e, ao mesmo tempo, possível fonte de alienação. No discurso da histérica, o sujeito do inconsciente com seus sintomas se dirige ao Outro (o Mestre), demandando que ele produza um saber sobre si. Por isso que, no que tange ao discurso do analista, também está presente a relação de mestria, revelando-se naquilo que o sujeito supõe que o analista lhe pode oferecer (Sujeito Suposto Saber): um saber sobre seu sofrimento. A diferença é que o analista subverte essa relação ao não aceitar o lugar do Mestre e promover a circulação do Sujeito Suposto Saber tanto na relação que se estabelece no tratamento individual quanto no em grupo.
Jasiner (2008), bem como outros autores, propõe que a rotação nos diferentes discursos é intrínseca à prática em instituições além de uma chave possível para se pensar as lógicas grupais e a maneira como se articula o desejo no laço social. Veremos adiante que a teoria dos discursos tem sido de grande valia para se pensar as relações, não só em relação aos grupos em situação clínica, mas também na convivência entre a equipe de trabalhadores.

\section{O coletivo não-todo}

No Seminário 20, ministrado em 1972, Lacan(2008) apresenta uma organização teórica inédita e subversiva para pensar a diferença entre os sexos a partir de duas lógicas opostas: a lógica do todo-fálico para os homens e a do não-todo para as mulheres, também correspondentes a duas formas diferentes de gozo, o fálico e o suplementar. Enquanto os homens herdariam da castração a sustentação fálica, a mulher se manteria em busca do lugar que ocupa, de um dizer especificadamente feminino. A consagração desse quantificador "não-todo", no sentido de pôr abaixo uma pretensão de totalidade, não situa só a partição sexual. As fórmulas abrem também para duas formas de se pensar o todo coletivo, como descreve Cevasco (2014): o todo com exceção do lado masculino e o não-todo sem exceção da posição sexuada feminina.

Vimos como é comum a tendência de um grupo buscar se reconhecer como um todo na homogeneização da massa em relação ao ideal. Aqui temos a exclusão do singular, remetendo ao imaginário das identificações numa “cola imaginária", como coloca Figueiredo (2005) resgatando Lacan. Sobre este olhar, Figueiredo (2005) também fornece algumas destas indicações da psicanálise lacaniana para pensar um coletivo que não se sustenta no todo. "Numa direção onde a Gestalt, que afirma que o todo é mais do que a soma das partes, afirmamos que não há todo na soma das partes." (p. 44). Isto quer dizer que o coletivo não-todo, que não se fecha, é diferente do coletivismo igualitário, que muitas vezes se impõe como garantia de um grupo. Jasiner (2008) corrobora com esta posição ao pensar o grupo desde uma lógica da incompletude, indicando que o coordenador trabalhará sabendo que não há palavra ou interpretação que possa cobrir de forma absoluta o real do grupo.

\section{A tópica lacaniana e o grupo}

A proposta de ordenar borromeicamente o trabalho grupal aparece em alguns trabalhos consultados, como Jasiner (2008) e Giraldo (2012). Recorrer à lógica borromeica ajuda a tarefa de coordenação (Jasiner, 2008, p. 31) para identificar as dimensões em excesso. Jasiner (2008) faz uma aproximação entre os conceitos de Freud e Lacan para descrever as dimensões em jogo: "narcisismoimaginário, do gozo-real ou supereu-simbólico" (p. 34), sendo este último geralmente manifesto nas posições sacrificantes assumidas por alguns quando se entregam ao próprio supereu. 
Giraldo (2012) aponta a importância da diferenciação entre diálogos no grupo e diálogo do grupo, de acordo com a posição na transferência, respectivamente imaginária ou simbólica. Nos diálogos no grupo, derivados do campo imaginário, os integrantes reagem aos outros e ao terapeuta desde uma posição na transferência relativa à relação com seu próprio ego, um produto do estádio do espelho, uma imagem de si mesmo formada na mais tenra infância, objeto da primeira alienação no homem numa imagem que funciona espontaneamente nos relacionamentos. É o que se chama de "espelhamento" na teoria psicanalítica e que se refere, para Lacan, à relação com o pequeno outro, relação que implica, então, na construção de uma imagem de si e do outro enquanto semelhantes. $\mathrm{O}$ autor diferencia o diálogo no grupo, derivado do campo imaginário da relação com o semelhante, do que chama de diálogos do grupo, correspondentes ao campo simbólico e da relação com o Outro, o que marcaria a diferença da relação de espelhamento para a singularidade do sujeito em sua relação com o Outro.

No espaço imaginário, o grupo se reconhece como parte de um todo e, se considerarmos seu aspecto mais primário, numa ilusão de unidade com a mãe. As tentativas de preservação narcísica da unidade grupal são exemplificadas nas falas que surgem no grupo: "sei como você se sente", "me sinto da mesma forma".

O conceito de Real está associado ao campo pulsional, ao trauma e ao irrepresentável. A referência ao gozo situa a dimensão pulsional no campo da satisfação e a forma como o sujeito se relaciona com o objeto $a$. A satisfação pulsional não é equivalente ao prazer e, por este motivo, engloba a forma mais bruta de gozo, a angústia. De acordo com Giraldo (2012), o Real perpassa o grupo, e o trabalho sobre o pulsional pode criar condições novas para um gozo parasitário. A função do analista no grupo é operar entre o gozo e o desejo através do campo da linguagem, o simbólico. Vemos com frequência os signos do Real através das ansiedades geradas, os desconfortos, mal-estares e angústias gerados no decorrer de um acontecer grupal. As formas de gozo também dizem respeito ao modo de enlaçamento social do sujeito e, nestes exemplos, vemos formas distintas de como cada um se coloca como objeto de gozo do Outro, ou seja, como o sujeito determina sua abertura ao Outro. O grupo, assim, pode ser potente no questionamento destas posições de gozo para novas formas de se relacionar no laço social.

\section{Trabalhos com grupos de extração lacaniana}

Apesar da fecundidade do pensamento de Lacan para se pensar os grupos, a construção e prática com dispositivos clínicos se iniciou somente com seus seguidores, especialmente por aqueles que buscavam desenvolver suas ideias no âmbito institucional.

Um deles foi Fracesc Tosquelles que, influenciado pela tese de Lacan sobre a paranoia (1932/1975), propôs a entrada da psicanálise para o tratamento de psicóticos no Hospital Psiquiátrico de Saint-Alban no sul da França durante a Segunda Guerra Mundial (Kupfer, Faria, \& Keiko, 2007). Dentre os dispositivos criados por Tosquelles, "o clube terapêutico", que posteriormente serviu de inspiração para Jean Oury e Felix Guattari na Clínica La Borde, consistia num conjunto de atividades de livre adesão e cogestão entre os pacientes que, posteriormente, se aproveitou da lei francesa, que em 1958 passou a viabilizar atividades associativas no manicômio (Ruiz et al., 2013).

Outros psicanalistas da Escola Francesa, preocupados com as articulações entre clínica e instituição, foram Maud Mannoni e Robert Lefort, que se debruçaram sobre o tratamento institucional das psicoses infantis com a fundação da Escola Experimental de Bonneuil em 1969, uma instituição mista entre escola e hospital-dia. Atualmente na França, Bernard Penot coordena um hospital-dia para adolescentes do Parque Montsouris em Paris, o Centre de Réadaptation Psychotérapique (CEREP), fundado em 1964 para o tratamento das psicopatologias graves na adolescência. Em entrevista realizada em 2001, o psicanalista discorre sobre os impasses do tratamento de casos nos quais o présubjetivo, relativo ao real lacaniano, transita entre o que não é imaginário e o que não é simbolizável. Nessa clínica, se ressalta o que ocorre no grupo, que vai muito além de um ato interpretativo, já que as situações manifestas no grupo precisam ser vivenciadas por todos, pacientes e equipe, antes de serem trabalhadas. Penot recorre ao seminário da carta roubada para melhor explicar a ideia de que a equipe viva a distribuição transferencial antes de realizar qualquer síntese clínica (Penot, 2002).

$\mathrm{Na}$ Argentina, Jasiner (2008) tem contribuído fortemente na reflexão sobre o trabalho grupal para as "patologias de borda" como refere, fazendo uma articulação entre as propostas de Pichon-Rivière e Lacan. Aos grupos centrados na tarefa (GCT), explorados por Pichon-Rivière (2000), a psicanalista acrescenta a abordagem borromeica lacaniana e a teoria dos discursos para o trabalho clínico com grupos.

Em Londres, Giraldo (2012) também se aproveita da tópica lacaniana para desenvolver seu pensamento sobre o trabalho com grupos em sua prática clínica, diferenciando o que chamou de diálogos no grupo (registro imaginário) dos diálogos do grupo (registro simbólico).

Na Espanha, em 2013, os movimentos sociais emergentes reuniram alguns psicanalistas dispostos a pensar a lógica coletiva lacaniana diante dos agrupamentos horizontais e sem partido de jovens protestando nas ruas. $\mathrm{O}$ resultado destas reflexões foi apresentado no evento sobre a subjetividade e as lógicas coletivas e no livro Política de lo real: nuevos movimentos sociales y subjetividade (Gallano, 2014a). Gallano (2014b) considera o tempo lógico a chave para os processos de subjetivação criativa em oposição à alienada. Diante dos mecanismos de poder e os colapsos de ordem simbólica, 
a noção de lógica coletiva em Lacan pode servir como orientação para se pensar o laço entre o singular e o comum, na qual os sujeitos se relacionam sem um chefe, em pé de igualdade e em torno de uma tarefa comum: uma saída para um problema social.

No Brasil, algumas propostas vêm sendo pensadas em diferentes perspectivas clínicas que buscam novas alternativas de tratamento através dos grupos em situações clínicas que colocam um limite à abordagem em consultórios.

Seguindo o norte das práticas democráticas instauradas a partir da década de 1980 no Brasil e das atuais políticas no atendimento em saúde assentadas nas diretrizes do Sistema Único de Saúde (SUS) e da reforma psiquiátrica, grande parte dos serviços de saúde mental, públicos ou privados, sustentam a prática clínica a partir dos espaços coletivos. Figueiredo (2005) argumenta que o recurso ao coletivo é uma característica privilegiada dos Centros de Atenção Psicossocial (CAPS) e uma marca já definida da "clínica ampliada". De acordo com a autora, o trabalho coletivo se dá por meio de diferentes propostas de intervenção, como as oficinas terapêuticas, os grupos de pacientes, grupos de familiares, atividades conjuntas de lazer, assembleias etc.

Algumas instituições psicanalíticas também buscaram acompanhar a transformação do modelo psiquiátrico no Brasil, como o hospital-dia A Casa, fundado em 1978, que propôs um novo modelo de atendimento a pacientes psicóticos apoiado na psicanálise de inspiração francesa (Lacan, Aulagnier, Fedida), na clínica de grupos na Argentina, a partir de PichonRivière, e na teoria da análise institucional, a partir de Deleuze e Guattari (Okamoto, 2017). O Lugar de Vida, instituição destinada ao tratamento de crianças psicóticas e autistas, recorre a aportes teóricos lacanianos para se pensar o dispositivo clínico grupal no tratamento. Vinculado à Universidade de São Paulo, o Lugar de Vida propiciou a Kupfer e outros pesquisadores pensar os grupos como dispositivo de tratamento capaz de produzir extensões nas inscrições primordiais da criança e como um campo produtivo para tratar o Outro. Inicialmente adotada por uma instituição belga, o tratamento do Outro foi pensado por Zenoni (1991) a partir da análise da incidência subjetiva do Outro na dimensão institucional (Kupfer, Faria, \& Keiko, 2007).

A prática das equipes de trabalho também vem sendo pensadas por diferentes psicanalistas de extração lacaniana. Rinaldi (2013), por exemplo, considera que a inserção do psicanalista nos espaços institucionais tem duas dimensões imbricadas: por um lado a "psicanálise em intensão", que diz respeito à clínica singular de cada sujeito, na qual também o real da psicose ou da neurose grave soma-se ao desamparo psíquico e social; por outro lado, a "psicanálise em extensão", no qual o psicanalista opera a partir de sua ética, que coloca o sujeito e seu desejo em primeiro plano em meio à "prática entre vários", ao trabalho em equipe.
Para Rinaldi (2013), a rotação dos quatro discursos, apontada por Lacan em "Radiofonia", texto de 1970, é uma ferramenta importante no exercício da clínica, na medida em que traz à tona os furos dos discursos, o impossível do real que se apresenta e, também, a possibilidade da sustentação deste furo no saber e a inventividade da clínica de cada sujeito. Outros autores que também consideram a clínica dos discursos uma ferramenta essencial para a vida institucional são Moretto e Priszkulnik (2014), que se basearam na rotação discursiva para pensar "a inserção e o lugar do psicanalista nas equipes de saúde”; e Dunker e Neto (2015), na medida em que a teoria dos discursos na instituição contribui para se pensar o manejo da transferência. Figueiredo (2005) destaca a concepção lacaniana do coletivo não-todo e da transferência de trabalho para se pensar o real da clínica, manifesto nas situações cotidianas das equipes de saúde. O tratamento do Outro, proposto por Zenoni (1991), norteia também o trabalho da equipe que, de acordo com Kupfer, Faria e Keiko (2007), pode propiciar uma gama de possibilidades de intervenção ao estilo de cada profissional da equipe se houver lugar para o sujeito "suposto não-saber", em oposição ao insuportável que é a intrusão e a dependência do Outro.

Um último exemplo sobre o funcionamento de equipes, formalizado a partir dos princípios da psicanálise lacaniana é o projeto Clínica Aberta de Psicanálise, iniciativa gratuita e que ocorre em espaços públicos, realizada em São Paulo desde o final de 2016. Suas três versões (clínica pública de psicanálise da Vila Itororó e as clínicas abertas na Casa do Povo e na Praça Roosevelt) consistem num dispositivo pautado na transferência do sujeito com um grupo de analistas que sustentam um desejo comum no exercício da função do analista, pautado, por sua vez, em uma falta em termos de saber (Marino, Coaracy \& Oliveira, 2018). Os idealizadores e participantes do projeto consideram que o dispositivo evita efeitos de identidade em torno do Ideal de Eu dos grupos tipo massa ou mesmo da situação dual de consultório, em que se forma a partir do binômio da massa (eu e ideal de eu).

Citamos também como os grupos no campo jurídico que atuam no atendimento de famílias associam-se ao trabalho grupal. Cerruti (2007), descrevendo a experiência com grupos no campo da mediação familiar, considera que o acompanhamento por outros pares dilui a autoridade do coordenador e evidencia a troca de experiências com quem compartilha os mesmos códigos (no caso, a população de baixa renda) faz com que opiniões diretivas, como "você deve fazer isto" ou "isto está errado", não gerem constrangimento, mas sim associações entre os integrantes que oferecem subsídios para que o universo fantasmático de cada um emerja.

Outro cenário no qual os psicanalistas estão pensando o grupo a partir de um resgate conceitual lacanianos é o de situações sociais críticas, situado nas bordas da intervenção clínica e social. O projeto 
"Migrantes, imigrantes e refugiados: vulnerabilidade e laço social", desenvolvido pelo Instituto de Psicologia da Universidade de São Paulo, foi um dos trabalhos visitados para pensar sobre o nexo entre a vulnerabilidade psíquica e os aparatos coletivos. O trabalho deste grupo destaca a importância das estratégias de elaboração coletiva do trauma diante da condição de exclusão, errância, abandono ou miséria. Trata-se de um sem-lugar no discurso, como descreve Rosa (2002).

O projeto Casa dos Cata-Ventos, fruto da parceria entre o Instituto de Psicologia da Universidade do Rio Grande do Sul e o Instituto da Associação Psicanalítica de Porto Alegre (APPOA) traz também uma proposta de acolhimento de pessoas em situação de extrema precariedade socioeconômica e exclusão social. Este trabalho propõe a possibilidade da inclusão e do reconhecimento através de um ato clínico e político, de aposta de existência de um sujeito de desejo que possa narrar sua história (Gageiro et al., 2015). A ação psicanalítica em situações sociais limites levaram também Broide (2010) a realizar diversas experiências com grupos sob o marco teórico de Enrique PichonRivière, Freud e Lacan. O grupo, de acordo com o autor, é um espaço poroso que coloca em cena o conflito do sujeito com o Outro, podendo ser fonte de "alienação do sujeito em massa, ou de apropriação do desejo pelo próprio sujeito no encontro com o Outro" (Broide, 2010, p. 44). A aposta no contexto grupal que situa o valor terapêutico do testemunho público sobre uma experiência traumática está igualmente presente no projeto Clínicas do Testemunho. A clínica do testemunho sustenta-se no tratamento da presentificação do real traumático que não pode ser simbolizado, tratamento que tem como base a declaração do sujeito acerca deste gozo intrusivo. Lacan sugere, no Seminário 20 (2008), que o testemunho diz respeito ao sujeito do inconsciente, no encontro com o enigma do Outro, cuja presença invasiva continua a ser sentida de forma insuportável para o sujeito e que é esse o gozo que precisa ser declarado a outro. De acordo com Ocariz (2015),

Quando ainda não há palavra há muita angústia impensável. Compartilhar sentimentos, expressar ideias, pensamentos, alivia a dor. Quando compartilhamos com o Outro, encontramos um lugar dentro de nós e pode-se então dar destinos criativos e construtivos ao quantum libidinal ligado a uma vivência traumática. (p. 36)

Corroborando com esta ideia, o projeto formou núcleos de apoio e de atenção psicológica em São Paulo, Rio de Janeiro, Porto Alegre e Recife aos afetados pelo trauma social e pela violência do Estado e dos governos autoritários.

Diversos eventos aconteceram também no Brasil para abordar a inserção da psicanálise no campo político e nos movimentos sociais, intensificados diante da degradação crescente de condições sociais. Em junho de 2018, Maria Rita Kehl, Tales Ab'Saber e Guilherme Boulos (2018) organizaram o evento intitulado "A luta que cura: a função terapêutica dos movimentos sociais". De acordo com os autores, as militâncias ajudam o sujeito a sair de uma narrativa de sofrimento e impotência para uma posição de luta e resistência.

\section{Os grupos na prática clínica}

Para operar num grupo psicoterapêutico para além do imaginário, Costa-Rosa e Pastori (2011) propõem as mesmas bases da análise individual para o grupo, mas com algumas modificações. Ela inicia-se a partir das entrevistas preliminares adaptadas a situação grupal, composta de três funções, como destaca Quinet (2005): sintomal, transferencial e diagnóstica. Na fase sintomal, o sujeito deve falar e o analista relançar o discurso do analisante, no intuito de que a queixa se transforme num sintoma a ser interrogado. No grupo, isto deve ocorrer da mesma forma e os novos integrantes têm o acréscimo dos outros membros nas primeiras escutas.

A partir da interrogação do sintoma, o sujeito encarna na figura do analista a função de Sujeito Suposto Saber, estabelecendo a transferência, condição necessária para o trabalho analítico. Tomando a teoria dos discursos, o estabelecimento da transferência também se refere à histericização do discurso, na qual o sujeito se dirige ao Mestre para que produza um saber sobre si, constituindo uma dimensão imaginária da transferência. A dimensão simbólica consiste no deslocamento da suposição de saber de um outro para o Grande Outro como simbólico. Assim, o sujeito é capaz de tratar a relação com o Outro e com o sofrimento derivado desta. O caminho da transferência imaginária para a simbólica depende da suspensão da mestria e do lugar de suposto saber pelo analista. Só assim é possível evitar a estagnação na transferência imaginária e permitir o deslocamento para a "transferência de trabalho" dentro da lógica coletiva nos grupos. O que caracteriza o analítico no grupo, portanto, é o trabalho na transferência, isto é, a extração do simbólico daquilo que está sendo colocado na realidade com as pessoas.

Suspendendo a mestria e as respostas, o analista favorece a abertura ao inconsciente, permitindo o aparecimento de um novo saber pelo retorno da questão ao sujeito sobre si mesmo. A passagem da transferência imaginária para a transferência de trabalho é também a passagem discursiva do Discurso da Histeria (analista no lugar do Mestre) ao discurso do Analista. No discurso do Analista, o analista opera a partir da "ignorância douta", como agente, semblante do objeto (a) (como causa, aquele que "faz" o outro falar), tal qual concebe Lacan (1998) e o sujeito está no lugar de trabalho (Costa-Rosa \& Pastori, 2011).

No que tange às transferências laterais, alguns membros do grupo também podem ser colocados no lugar do Mestre por outros. É comum que algum paciente exerça a função de coterapeuta e, por isso, é importante que o 
terapeuta cuide para que a oferta de respostas prontas não impeça o sujeito de encontrar seus próprios sentidos, como reiteram Costa-Rosa e Pastori (2011), "o sentido produzido pelos próprios sujeitos é o único capaz de dar conta do gozo em jogo no sofrimento ou nas formações sintomáticas que os fizeram vir" (p. 10).

Lacan buscou recentrar a teoria psicanalítica no plano do desejo. O desejo se sustenta a partir de uma fantasia sobre um outro imaginário que engana o desejo para encobrir a falta-a-ser (a incompletude). Com isto, Lacan estabeleceu uma relação entre o desejo calcado no reconhecimento do outro (ou desejo do desejo do Outro) e o desejo inconsciente (a realização no sentido que Freud empregou) (Roudinesco \& Plon, 1998). Desta forma, a direção do tratamento dentro de um campo clínico grupal é contribuir para o deslizar do desejo do reconhecimento (alienação ao desejo do Outro) para o reconhecimento do próprio desejo (separação do desejo do Outro), processo no qual se faz necessário que o desejo do analista contemple o projeto de que o sujeito produza sua diferença e sua marca singular ao resgatar a alteridade numa forma de laço inédita.

Vimos que o Mais-Um é a proposta lacaniana para a organização de um grupo marcado pela ausência de um significante Mestre que o comande. A função do Mais-Um é manter a falta do saber e a carência de poder em cada um. A solução, por sua vez, depende do ato de cada um, mas que só existe diante de um ato recíproco dos outros. É por isso que a lógica coletiva proposta por Lacan é antialienante, no sentido da alienação das massas, e anti-individualista.

A grupalização ocorre na iminência dos dois discursos (da Histeria e do Analista). No primeiro momento, tem-se a impressão de que os problemas são comuns. O analista, situado transferencialmente de forma a relançar a enunciação, contribui para que o encontro de dois significantes vindos de diferentes sujeitos no grupo permita a um terceiro sancionar um sentido singular e deslocar sua posição em relação ao sintoma. Trata-se de um trabalho conjunto que depende da circulação da palavra (associação significante) e do relançamento dos enunciados (individual e transindividual) para produzir a dimensão da enunciação, capaz, por sua vez, de produzir um reposicionamento subjetivo (Costa-Rosa \& Pastori, 2011). Seguiremos com uma pequena anedota ilustrativa.

\section{Ressonância de significantes: a função do semelhante no grupo}

A báscula constante do grupo entre efeito massa e efeito sujeito pode encontrar na ressonância de significantes entre os sujeitos um encontro produtivo para o trabalho no singular, especialmente nos casos nos quais a capacidade de acessar o simbólico encontra-se reduzida. Um exemplo se passa num grupo no qual uma mulher se queixava de estar sendo "torturada" num delírio de perseguição. Num outro grupo, na ausência desta mulher, uma jovem diz que também se sentia "torturada" quando estava em crise, perguntando se isso seria uma coisa comum das pessoas em crise. O terapeuta então lhe pergunta sobre como é a tortura. A moça então diz tinha um sentimento de ser "torturada" pelos outros, mas ao ver a outra mulher, pensava agora que poderia ser "alguma coisa minha que me consumiu no momento de crise".

Vimos neste simples fragmento clínico que o semelhante exerceu uma função no grupo a partir da ressonância de um significante, no caso a "tortura" (alguém que sofre como eu). A elaboração se desenrola a partir do momento em que o terapeuta lhe reenvia o significante que, apesar de não ter sido originalmente dito por ela, abre sua própria cadeia significante. Houve então um direcionamento que contribuiu para uma mudança da posição de objeto de gozo do Outro (ser torturada) para algo possível de ser enfrentado pelo sujeito (a tortura em mim).

Se nos remetermos novamente ao tempo lógico, vemos uma relação de reciprocidade entre semelhantes que questiona o olhar deste grupo as escansões temporais: ver o outro em seu sofrimento, compreender no outro um ponto de ressonância e concluir, a partir da relação de reciprocidade, o que se passa consigo mesmo. A função do coordenador do grupo é fundamental no trabalho de conduzir as ressonâncias à produção singular, operando para que os membros do grupo tentem se deslocar de uma tentativa de "ajudar" o outro para uma associação com sua própria história. $\mathrm{O}$ grupo flutua no poder da identificação e o coordenador ajuda através de uma “vigilância simbólica", como reflete Giraldo (2012, p. 98).

\section{Diagnóstico no grupo}

Por último, a função diagnóstica é fundamental para se definir a direção do tratamento. Esta também é possível de se realizar nos grupos, já que é feita sob transferência. Contudo, temos condições, por meio da palavra, de colocar organizações psíquicas distintas em um grupo de modo a operar a direção do tratamento adequada para cada sujeito?

O significante da lei, o Nome-do-Pai, estabelece uma função central organizadora na neurose, a castração simbólica, mas está foracluída na psicose. O efeito da foraclusão do Nome-do-Pai, que cumpre nas neuroses a função de ponto de basta, é um Outro sem o significante da lei e, por isso, um Outro absoluto ao qual o sujeito psicótico está submetido. É por isso que na psicose, como coloca Quinet (2006), o analista deve manobrar a transferência com o objetivo estratégico de barrar o gozo do Outro.

\section{Neurose e psicose: uma tensão que se estabelece no acontecer grupal}

Existe uma série de tensões no acontecer grupal derivada do convívio entre as diferentes estruturas. Giraldo (2012) assinala que o "inconsciente a céu aberto" (Lacan, 1958b/1998) na psicose, não mediado pelo simbólico, traz à tona a dimensão do Real que provoca angústia aos 
neuróticos. Os neuróticos acabam por tomar o psicótico como irracional, pois desorganiza seu sistema simbólico. Em contrapartida, na psicose, o discurso neurótico pode ser invasivo. É comum num grupo um sujeito psicótico se sentir perseguido por outro ou invadido quando há algum tipo de contato corporal, como, por exemplo, um paciente em um grupo que, ao ser tocado, considerava que haviam lido seu pensamento. Do outro lado, o exemplo se passa em uma oficina terapêutica, onde, diante de uma tarefa em comum, um sujeito neurótico se irritava com a falta de andamento do projeto, buscava organizar as tarefas de todos e sentia-se frustrado com a falta de engajamento dos que não estavam submetidos à norma fálica.

O trabalho do analista no grupo deve levar em conta estas diferenças. A interpretação, na neurose, contempla ao mesmo tempo a abertura significante para o sem sentido e os efeitos de sentido, com vistas a mudar a posição do sujeito em relação ao sofrimento. Nas psicoses, o analista deve agir com precaução para não interpretar o delírio tal como na neurose, já que a possibilidade de simbolização não opera da mesma maneira.

\section{Oficinas e grupos de atividades em saúde mental}

Os grupos que envolvem uma atividade sempre foram um recurso muito utilizado na história da saúde mental. Por isso, é importante trazer algumas especificidades na prática clínica do psicanalista nestes grupos que envolvem um objeto intermediário ou uma tarefa em comum. Os grupos de terapia ocupacional, oficinas terapêuticas e os grupos temáticos são geralmente evocados quando se fala nas propostas de tratamento advindas da reforma psiquiátrica. Neste universo, não existe um modo único de intervenção. Tais dispositivos são quase sempre sustentados por diferentes maneiras de produção e de criação a partir de uma multiplicidade de linguagens, o que pode incluir a produção artística, intelectual, trabalho coletivo, entre outras formas.

Diferente dos grupos verbais, ou "egoterápicos" como coloca Kaës (2010), a função da fala nestes grupos é posterior à experiência com o objeto ou com o trabalho. Neste trabalho, os coordenadores se abstêm do objetivo interpretativo, sob a condição de que a fala surja de forma secundária e possa facilitar a atividade de elaboração em decorrência da experiência pulsional. É o objeto mediador que dispara o processo associativo no que tange tanto às relações entre o sujeito e o objeto, quanto àquilo que envolve as relações entre os objetos de cada um e do outro com os seus.

Pensando com Lacan, os grupos que envolvem uma atividade têm um duplo registro através do ato criativo: o sujeito e sua criação, e a criação do sujeito com outros. Os objetos mediadores funcionam como um "meio", uma estratégia para acessar o simbólico. $\mathrm{O}$ ato criativo, não necessariamente está ligado à criação artística, mas à criatividade. Do lado do analista, o ato analítico comporta criatividade e, do lado do analisando, impulsiona o trabalho de elaboração, que pode encaminhar-se para o ato criativo, numa articulação entre o trabalho analítico e sublimação e, ainda, entre sublimação, ato criativo e subjetividade. $\mathrm{O}$ ato criativo com outros é $\mathrm{o}$ acontecimento que pode ser armado para que haja as melhores condições para que o sujeito possa falar em nome próprio.

Cabe aqui um breve comentário acerca do tema da sublimação na psicose. Não cabe aqui desenvolver esta discussão, mas apontar que existe um paralelo entre a sublimação na neurose e o sintoma na psicose, uma suplência do "pai" sustentada a partir da invenção e da produção singular do sujeito. Ainda assim, autores como Pommier (1990), que fazem um paralelo entre sublimação e sintoma, enfatizando a possibilidade da sublimação na psicose nos termos de sustentação subjetiva.

Pensar a criação com outros, via sublimação, nos remete também à noção de testemunho, ou seja, a um reconhecimento do Outro que tem a função de promover o laço social. Aí a sublimação aparece não somente como desvio da finalidade sexual, como renúncia ou como mudança de destino pulsional. Como coloca Jasiner (2008), a sublimação supõe também uma valorização do coletivo, "um trabalho do coletivo sobre a pulsão" (p. 42). Ainda assim, ela ressalta que não se deve perder de vista a articulação entre o que se produz no coletivo e o traçado das marcas singulares, o que é próprio à psicanálise. A partir de Lacan, a autora complementa que a criação, por fim, "produz um simbólico que processa de maneira apaziguante o impossível do real" (Jasiner, 2008, p. 43) Corroborando com esta ideia, Costa (2015) assinala que em situações nas quais existe a experiência compartilhada da arte, institui-se um suporte social para fazer borda ao gozo.

\section{Concluindo: por que pensar o grupo a partir do referencial lacaniano hoje?}

É pelo mal-estar contemporâneo que podemos inferir, mais do que a dinâmica do grupo em si, a importância do recurso ao grupo no trabalho clínico da articulação posta entre aquilo que tange a dimensão mais íntima do ser, o desejo, com a dimensão coletiva, representada pelo campo grupal. A exacerbação do individualismo, a carência de referências subjetivas para a identificação e a degradação das condições de trabalho e dos direitos sociais tornam o grupo um instrumento clínico e político, tanto para as situações sociais limites, nas quais a precariedade social soma-se à precariedade das possibilidades de subjetivação, quanto para as situações clínicas limites, que incluem as psicoses, a depressão, drogadição e outras patologias borderline. A vulnerabilidade psíquica sob o excesso de real não simbolizado torna a sustentação operada pelos grupos um exemplo de suplência produtiva dentro da abordagem clínica.

É a ética, e não o setting analítico, o que rege os atos do analista, tal como pontuou Lacan (1958a/1998) ao enfatizar que a política e a ética do 
psicanalista enquadram as táticas e estratégias. Segundo Quinet (2009), Lacan evoca a política da psicanálise como antídoto ao poder da transferência: "Lá onde o analista poderia exercer o poder - poder que a própria transferência lhe confere - ele faz o exercício da falta" (p. 43). A política da falta-a-ser, se engendra, por fim, na ética da psicanálise, que é a ética do desejo.

O projeto de estudar os elementos que podem servir de base para pensar os grupos a partir da psicanálise lacaniana nos colocou diante da tarefa de extrair certas bases do pensamento sobre o coletivo. Nesta retomada, se produziu um estatuto para o grupo com a preocupação de compreender como intervir no sofrimento daquele sujeito que escapa ao corpo social, aproveitando-se e afastando-se do campo imaginário, operando clinicamente, e de forma constante, um deslizamento da demanda de reconhecimento, das posições cristalizadas de gozo, para a criação de novas formas de laço social a partir do reconhecimento do próprio desejo. Os grupos, assim como outros dispositivos clínicos, não são nem melhores, nem piores que a análise individual. Eles exercem uma função que depende de como se opera e se constrói o dispositivo, como se circulam as tensões entre o efeito imaginário e o efeito sujeito, entre as diferentes estruturas clínicas, como se questiona o lugar do Mestre e como os gozos são reordenados a partir destas operações.

\section{What makes the group an analytical device? Freud's and Lacan's considerations}

Abstract: The objective of this article is to resume the discussion on clinical practice with groups based on the psychoanalysis of Freud and Lacan, aiming at emphasizing the psychoanalyst's ethics, its impasses and its possibilities of insertion in collective, public or institutional environments. The use of the collective is a privileged characteristic in psychosocial care and in the "expanded clinic" recommended by the Unified Health System (SUS). However, it is often seen the dilution of the innovative perspective proposed in the emergence of groups in the clinical field and the predominance of mass care, which justifies this clinical resumption. For such purpose, we present counterpoints between groupists within psychoanalysis and the Lacanian perspective on collective logic and the social bond. Then, we return to some studies of Lacanian extraction in different collective contexts and, finally, we emphasize some considerations about clinical practice, aiming at crossing the imaginary effects of the group and privileging the subject and its uniqueness.

Keywords: psychoanalysis, groups, institutions, Freud, Lacan.

\section{¿Qué hace del grupo un mecanismo analítico? Consideraciones de Freud y de Lacan}

Resumen: El propósito de este artículo es retomar la discusión sobre la práctica clínica con grupos a partir del psicoanálisis de Freud y de Lacan con el fin de resaltar la ética del psicoanalista, sus impasses y posibilidades de inserción en espacios colectivos, públicos o institucionales. El recurso del colectivo es una característica privilegiada en la atención psicosocial y en la "clínica ampliada" recomendada por el Sistema Único de Salud (SUS). Sin embargo, suele haber una dilución de la perspectiva innovadora propuesta en la emergencia de grupos en el campo clínico y el predominio de la atención masiva, lo que justifica esta reanudación clínica. Para ello, se presenta contrapuntos entre los grupos del psicoanálisis y la perspectiva de Lacan sobre la lógica colectiva y el lazo social. Después, se vuelve a algunos trabajos de extracción lacaniana en diferentes contextos colectivos para, por último, enfatizar algunas consideraciones sobre la práctica clínica, con el objetivo de atravesar los efectos imaginarios del grupo y privilegiar al sujeto y su singularidad.

Palabras clave: psicoanálisis, grupos, instituciones, Freud, Lacan.

\section{Qu'est-ce qui fait du groupe un dispositif analytique ? Considérations de Freud et Lacan}

Résumé: Cet article aborde la pratique clinique avec des groupes basé sur la psychanalyse freudienne et lacanienne, en visant à souligner l'éthique du psychanalyste, ses enjeux et ses possibilités d'insertion dans des espaces collectifs, publics ou institutionnels. L'appel au collective est une caractéristique privilégiée du soin psychosociale et de la « clinique élargi » conçu par le Système de Santé Unifié (SUS). Cependant, nous constatons souvent la dilution de la perspective innovatrice proposée dans l'émergence de groupes dans le domaine clinique et la prédominance des soins en masse, justifiant cette reprise clinique. Pour ce faire, nous présentons des contrepoints entre les groupistes au sein de la psychanalyse et la perspective lacanienne sur la logique collective et le lien social; ensuite, nous reprenons quelques études d'extraction lacanienne dans différents contextes collectifs. Enfin, nous soulignons quelques considérations sur la pratique clinique, en cherchant à franchir les effets imaginaires du groupe et à privilégier le sujet et sa singularité.

Mots-clés: psychanalyse, groupes, les institutions, Freud, Lacan. 


\section{Referências}

Askofaré, S. (2009). Da subjetividade contemporânea. A Peste, 1(1), 165-175.

Anzieu, D. (1993). O grupo e o inconsciente (o imaginário grupal). São Paulo, SP: Casa do Psicólogo.

Bion, W. (1961/1975). Experiências com grupos. Rio de Janeiro, RJ: Imago.

Broide, J. (2010). A psicanálise nas situações sociais críticas: violência, juventude e periferia em uma abordagem grupal. Curitiba, PR: Juruá.

Cavalcanti, A. (2006). Ser brincando: sobre a psicanálise em grupo com as crianças. In P. S. Rocha (Org.), Cataventos: invenções na clínica psicanalitica institucional (pp. 133-155). São Paulo, SP: Escuta.

Cevasco, R. (2014). Acto y saber en la lógica colectiva de Lacan. In C. Gallano (Coord.), Politica de lo real: nuevos movimientos sociales y subjetividad (pp. 115-144). Barcelona: Ediciones S\&P.

Cerruti, M. (2007). Bate-se em uma mulher: impasses da vitimização (Tese de Doutorado). Instituto de Psicologia, Universidade de São Paulo, São Paulo.

Costa, A. (2015). Litorais da psicanálise. Rio de Janeiro, RJ: Escuta.

Costa-Rosa, A., \& Pastori, F. (2011). O grupo psicoterapêutico para além do imaginário: a psicanálise de Lacan, laços sociais e revoluções de discurso. Revista de Psicologia da Unesp, 10(1), 1-23.

Dunker, C., \& Neto, F. (2015). Psicanálise e saúde mental. Porto Alegre, RS: Criação Humana.

Figueiredo, A. (2005). Uma proposta da psicanálise para o trabalho em equipe na atenção psicossocial. Mental, 5(3), 44-55.

Freud, S. (2006). Totem e Tabu. In Edição standard brasileira das obras psicológicas completas de Sigmund Freud (J. Salomão, trad., Vol. 13, pp. 21-168). Rio de Janeiro, RJ: Imago. (Trabalho original publicado em 1913).

Freud, S. (2006). Sobre o Narcisismo: uma introdução. In Edição standard brasileira das obras psicológicas completas de Sigmund Freud (J. Salomão, trad., Vol. 14, pp. 81-113). Rio de Janeiro, RJ: Imago. (Trabalho original publicado em 1914).

Freud, S. (2006). Luto e Melancolia. In Edição standard brasileira das obras psicológicas completas de Sigmund Freud (J. Salomão, trad., Vol. 15, pp. 245-265). Rio de Janeiro, RJ: Imago. (Trabalho original publicado em 1917).

Freud, S. (2006). Psicologia de Grupo e Análise do Ego. In Edição standard brasileira das obras psicológicas completas de Sigmund Freud (J. Salomão, trad., Vol. 18, pp. 79-145). Rio de Janeiro, RJ: Imago. (Trabalho original publicado em 1921).

Freud, S. (2006). O ego e o id. In Edição standard brasileira das obras psicológicas completas de Sigmund Freud (J. Salomão, trad., Vol. 19, pp. 27-72. Rio de Janeiro, RJ: Imago. (Trabalho original publicado em 1923).

Gageiro, A., Tavares, E., Almeida, R., Almeida, R. M. C., \& Torossian, S. D. (2015). Casa dos Cata-Ventos: uma estratégia clínica e política na atenção à infância. Correio
Appoa, 247. Recuperado de http://www.appoa.org.br/ correio/edicao/247/casa_dos_cata_ventos_uma_estrategia_ clinica_e_politica_na_atencao_a_infancia/226.

Gallano, C. (Coord.). (2014a) Politica de lo real: nuevos movimientos sociales y subjetividad (pp. 15-34). Barcelona: Ediciones S\&P.

Gallano, C. (2014b). Subjetividad y lógicas colectivas. In C. Gallano (Coord.), Política de lo real: nuevos movimientos sociales y subjetividad (pp. 15-34). Barcelona: Ediciones S\&P.

Giraldo, M. (2012). The dialogues in and of the group: lacanian perspectives on the Psychoanalytic group. Londres: Studio.

Gomes, L. (2015, 19 de outubro). O cartel como aposta política de Lacan. Recuperado de http://verdadelacaniana.blogspot. com.br/2015/10/o-cartel-como-aposta-politica-de-lacan.html

Kaës, R. (2010). Um singular plural: a psicanálise a prova de grupo. São Paulo, SP: Loyola.

Kehl, M. R., Boulos, G., \& Ab'Saber, T. (2018, 27 de junho). A luta que cura: a função terapêutica dos movimentos sociais [Vídeo]. São Paulo, SP: TV Boitempo. Recuperado de https:/www.youtube.com/ watch? $\mathrm{v}=\mathrm{da} 9 \mathrm{bcXpoCh} 0$.

Kupfer, M., Faria, C., \& Keiko, C. (2007). O tratamento institucional do Outro na psicose infantil e no autismo. Arquivos Brasileiros de Psicologia, 53(2), 156-166.

Jasiner, G. (2008). Coordinando grupos. Buenos Aires: Lugar.

Lacan, J. (1932/1975). De la psycose paranoique dans ses rapports avec la personnalité. Paris: Seuil.

Lacan, J. (1980). D’Écolage. Revista da Letra Freudiana, 1.

Lacan, J. (1995). O Seminário livro 4: a relação de objeto, 1956-1977. Rio de Janeiro, RJ: Zahar.

Lacan, J. (1945/1998). O tempo lógico e a asserção da certeza antecipada. In J. Lacan, Escritos (pp. 197-213). Rio de Janeiro, RJ: Zahar.

Lacan, J.(1958a/1998). A direção do tratamento e os princípios de seu poder. In J. Lacan, Escritos (pp. 591-652). Rio de Janeiro, RJ: Zahar.

Lacan, J. (1958b/1998). De uma questão preliminar a todo tratamento possível da psicose. In J. Lacan, Escritos (pp. 537-590). Rio de Janeiro, RJ: Zahar.

Lacan, J. (1966/1998) Função e campo da fala e da linguagem em Psicanálise. In J. Lacan, Escritos (pp. 238-324). Rio de Janeiro, RJ: Zahar.

Lacan, J. (1998). O seminário, livro 11: os quatro conceitos fundamentais da psicanálise, 1964. Rio de Janeiro, RJ: Zahar.

Lacan, J. (1947/2003). A Psiquiatria inglesa e a guerra. In J. Lacan, Outros Escritos (pp. 106-126). Rio de Janeiro, RJ: Zahar.

Lacan, J. (1967/2003). Proposição de 9 de outrubro de 1967. In J. Lacan, Outros Escritos (pp. 248-264). Rio de Janeiro, RJ: Zahar.

Lacan, J. (2006). O seminário, livro 17: o avesso da psicanálise, 1969-1970. Rio de Janeiro, RJ: Zahar. 
Lacan, J. (2008). O seminário, livro 20: mais, ainda, 19721973. Rio de Janeiro: Jorge Zahar.

Laurent, E. (2002). Lo realy el grupo.Cuatro +uno, 4. Recuperado de http://cuatromasuno.eol.org.ar/Ediciones/004/template. asp?Logicas-colectivas/Lo-real-y-el-grupo.html.

Lewin, K. (1978) Problemas de dinâmica de grupo. São Paulo, SP: Cultrix.

Marino, A., Coaracy, A., \& Oliveira, T. (2018). Uma experiência de clínica aberta de psicanálise. Lacuna, 5. Recuperado de https://revistalacuna.com/2018/06/04/n05-04/.

Moretto, M. \& Priszkulnik, L. (2014). Sobre a inserção e o lugar do psicanalista na equipe de saúde. Tempo Psicanalítico, 46(2), 287-298.

Ocariz, M.C. (2015). Violência de Estado na ditadura civil-militar brasileira (1964-1985): efeitos psíquicos e testemunhos clínicos. São Paulo, SP: Escuta.

Okamoto, M. (2017). Revisitando Enrique Pichon-Rivière: grupo interno, história de origem e contexto social (Dissertação de Mestrado). Pontifícia Universidade Católica de São Paulo, São Paulo.

Penna, C. (2014). O inconsciente social. São Paulo, SP: Casa do Psicólogo.

Penot, B. (2002). O CEREP e o hospital-dia para adolescentes do parque Montsouris [Entrevista cedida à Gislene Jardim]. Estilos da clínica, 7(12), 64-75.

Pichon-Rivière, E. (2000). O processo grupal. São Paulo, SP: Martins Fontes.

Pommier, G. (1990). O desenlace de uma análise. Rio de Janeiro: Zahar.

Pomponet, R. (2013). O cartel na Escola de Lacan. @gente: revista de psicanálise, (8), 24-30.
Porge, E. (1994). Psicanálise e Tempo: o tempo lógico de Lacan. (D. D. Estrada, trad.) Rio de Janeiro, RJ: Campo Matêmico.

Quinet, A. (2005). As $4+1$ condições da análise. Rio de Janeiro: Jorge Zahar.

Quinet, A. (2006). Teoria e Clínica da Psicose. Rio de Janeiro, RJ: Forense.

Quinet, A. (2009). A Estranheza da Psicanálise. Rio de Janeiro, RJ: Zahar.

Quinet, A. (2012). Os outros em Lacan. Rio de Janeiro, RJ: Zahar.

Rinaldi, D. (2013). Clínica, ética e política: a prática do psicanalista na instituição de saúde mental. In R. Barros (Org.), Psicanálise e Saúde: entre o estado e o sujeito (pp.115- 123). São Paulo, SP: Companhia de Freud.

Rosa, M. (2002). Uma escuta psicanalítica das vidas secas. Textura, 2(2), 42-46.

Roudinesco, E., \& Plon, M. (1997). Dicionário de Psicanálise. (trad. V. R. Magalhães) Rio de Janeiro, RJ: Zahar.

Ruiz, V., Athayde, V., Nogueira Filho, I., Souza, P., \& Athayde, M. (2013). François Tosquelles, sua história no campo da Reforma Psiquiátrica/Desinstitucionalização e suas pistas para uma abordagem clínica do trabalho centrada na atividade. Estudos e Pesquisa em Psicologia, 13(3), 855-877.

Zenoni, A. (1991). "Traitement" de l'Autre. Préliminaire, $110(3), 101-110$.
Recebido: 4/03/2018

Revisado: 19/09/2019

Aprovado: 3/03/2021 